\title{
On the design, laboratory model and performance of the controlled magnetic journal bearing for the DeepWind project
}

Ritchie, Ewen; Bjerregaard, Henning; Sloth, Kristian; Thygesen, Rune Ryberg; Schmidt Paulsen, Uwe

Published in:

Proceedings of Technologies and Materials for Renewable Energy, Environment and Sustainability

Link to article, DOI:

$10.1063 / 1.5117050$

Publication date:

2019

Document Version

Publisher's PDF, also known as Version of record

Link back to DTU Orbit

Citation (APA):

Ritchie, E., Bjerregaard, H., Sloth, K., Thygesen, R. R., \& Schmidt Paulsen, U. (2019). On the design, laboratory model and performance of the controlled magnetic journal bearing for the DeepWind project. In Proceedings of Technologies and Materials for Renewable Energy, Environment and Sustainability (1 ed., Vol. 2123). [030019] American Institute of Physics. AIP Conference Proceedings Vol. 2123 No. 1 https://doi.org/10.1063/1.5117050

\section{General rights}

Copyright and moral rights for the publications made accessible in the public portal are retained by the authors and/or other copyright owners and it is a condition of accessing publications that users recognise and abide by the legal requirements associated with these rights.

- Users may download and print one copy of any publication from the public portal for the purpose of private study or research.

- You may not further distribute the material or use it for any profit-making activity or commercial gain

- You may freely distribute the URL identifying the publication in the public portal 


\section{On the design, laboratory model and performance of the controlled magnetic journal bearing for the deep wind project}

Cite as: AIP Conference Proceedings 2123, 030019 (2019); https://doi.org/10.1063/1.5117050 Published Online: 17 July 2019

Ewen Ritchie, Henning Bjerregaard, Kristian Sloth, Rune Ryberg Thygesen, and Uwe Schmidt Paulsen

View Online

\section{Conference Proceedings}

Get $30 \%$ off all print proceedings!

\section{Enter Promotion Code PDF30 at checkout}

AlP 


\title{
On the Design, Laboratory Model and Performance of the Controlled Magnetic Journal Bearing for the Deep Wind project
}

\author{
Ewen Ritchie ${ }^{1}$, Henning Bjerregaard ${ }^{1}$, Kristian Sloth ${ }^{1}$, Rune Ryberg Thygesen ${ }^{1}$, \\ Uwe Schmidt Paulsen ${ }^{2 a}$ \\ ${ }^{1}$ Department of Energy Technology, Aalborg University, Denmark \\ ${ }^{2}$ Department of Wind Energy, DTU, Risø Campus, Denmark \\ ${ }^{a)}$ Corresponding author: uwpa@dtu.dk
}

\begin{abstract}
DeepWind has attracted scientific attention. This is due to its design simplicity, which will reduce costs for installation, operation and maintenance of a deep sea offshore wind generator system. Using this design offers advantages of alternative ways to manufacture the turbine rotor parts, introduce new materials, a novel way to implement a direct drive, Permanent Magnet Generator (PMG) and bearing technology, and a design that offers a reduced cost of energy. DeepWind uses a generator and bearings module, supported by controlled magnetic bearings technology. However, many technologies implemented in DeepWind are well known from other applications (e.g. Wind Energy, Sub-sea installations, Offshore installations). This paper presents the controlled magnetic bearings proposed for DeepWind.
\end{abstract}

\section{INTRODUCTION}

DeepWind is a vertical-axis wind turbine (VAWT) concept with the turbine rotor mounted on a floating spar buoy with journal bearings centering the generator at the bottom, Figure (Fig. ) 1a. It is described in the design concept and project outcomes [7, 8] as offering a big advantage by using the water as a huge bearing as one of the novelties for solving the technical challenges of placing the generator. The general nomenclature of the major components of the DeepWind VAWT system is shown in Fig. 1b. Ratings envisaged are up to $20 \mathrm{MW}$ [3]. The bearings connect the turbine system to the torque absorption- and mooring system and support rotation and differences in wind and flotation forces. Forces arise from the action of the wind on the turbine flotation, dynamic turbine rotor loads, unbalanced magnetic pull in the generator, the Magnus effect arising from a shaft rotating in moving water, etc. [2]. Challenges are to support all radial and axial components of forces reliably, at all times, on bearings mounted up to 300 [m] below sea level. Fig. 1c shows a simplified diagram of the forces acting on the bearings.

Plain bearings, rolling bearings and magnetic bearings were considered. A controlled magnetic bearing was proposed to enable shaft position control at rotation standstill and all other speeds, avoid mechanical wear, lubricant (pollutant) and losses. To achieve this, the bearings must be excited at all times. The bearings were modelled under steady state and dynamic conditions, Fig. 2a, and the model was verified using a laboratory model, sketched in Fig. $2 \mathrm{~b}$. 


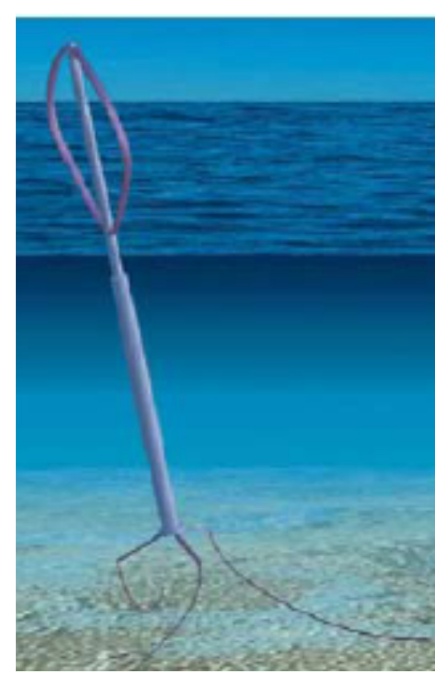

(a)

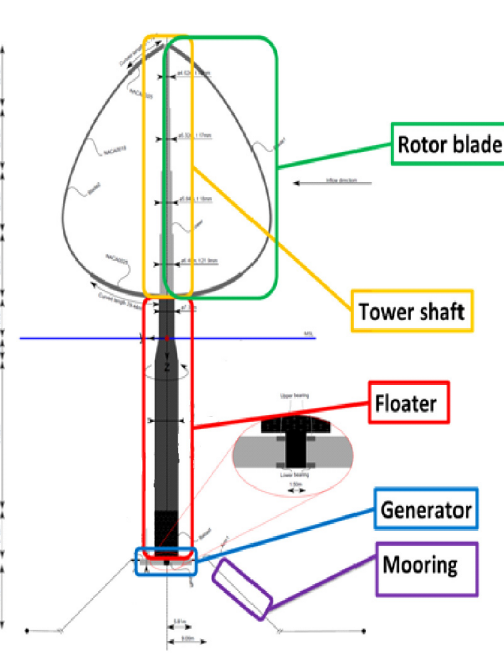

(b)

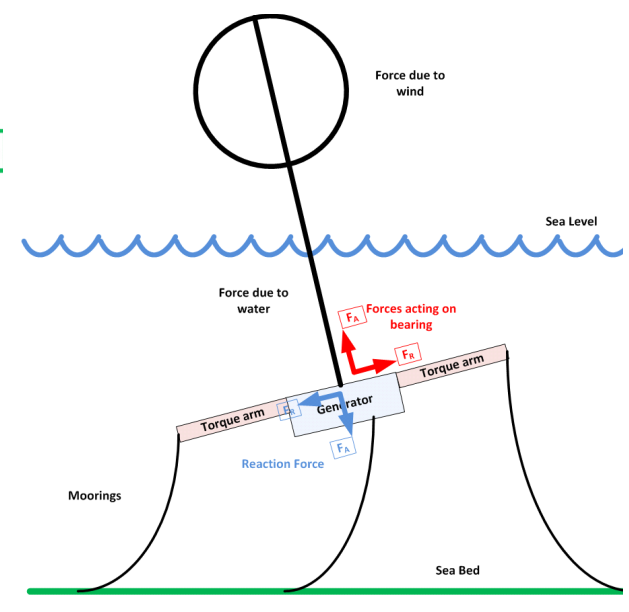

(c)

FIGURE 1. a) Illustration of DeepWind concept, [13]. b) Diagram of VAWT showing legend of terminology used, [7, 8]. c) Simplified diagram illustrating the forces acting on the DeepWind bearings [10].

The model was used to implement a design tool relating the forces to be supported to the dimensions and materials of the bearing required.

The controlled magnetic journal bearing is able to apply force in three radial directions as required; Fig. 2c, A controller and power electronics converter is implemented for each direction, on each bearing. Current flowing in the winding associated with a direction applies a force of attraction in that direction. Two thrust bearings each act in one direction only and provide reaction to forces acting along the axis of the shaft.

As an example, for the $5 \mathrm{MW}$ journal bearing version, at one time the design forces were estimated to be radial force mean $=471 \mathrm{kN}, \max =1336 \mathrm{kN}$ for the top bearing, when the shaft diameter was $5.5 \mathrm{~m}$, with $5.65 \mathrm{~m}$ length between the bearings and a bearing clearance (air-gap) of $0.01 \mathrm{~m}$. The bearing required 37.7 ton of electrical steel, and 1.7 ton of copper. The maximum DC power required to supply the forces was $208 \mathrm{~kW}$, but the mean power over time was $26 \mathrm{~kW}$.

The model used was verified by tests on the laboratory arrangement of Fig. 2b, [1]. In the figure, the two lower stators are journal bearings, and the upper stator is an actuator used to apply force. The shaft position was sensed for measurement and feedback purposes. Sample results are shown in Fig. 17, showing a step response of position for a simulated and tested shaft move in each of two directions.

Using this model, and an adaptation of it to model the thrust bearings, all the bearing calculations for the DeepWind project were made. There were several design iterations, as adjustments were made to the floater and tower designs to reduce the forces and optimise the size of bearing required for each position.

\section{SPECIAL CHALLENGES ASSOCIATED WITH THE DEEPWIND VAWT SYSTEM}

The only bearings on the DeepWind VAWT construction are the radial and axial bearings of the generator, Fig. 1c. These bearings must transmit all forces and moments from the shaft to the mooring system whilst ensuring concentricity of the air-gap between the rotor and stator. 


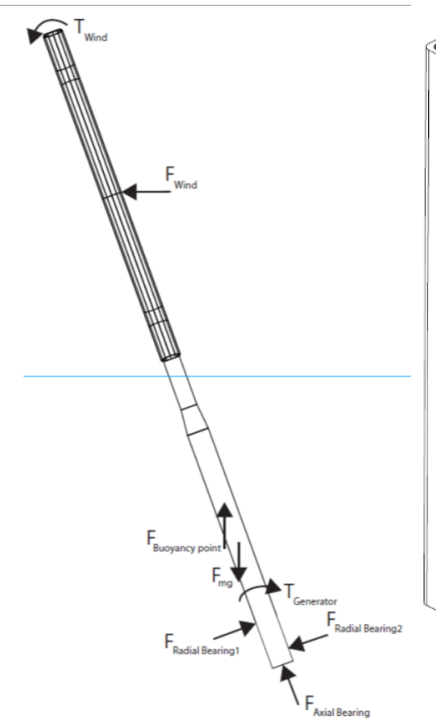

(a)

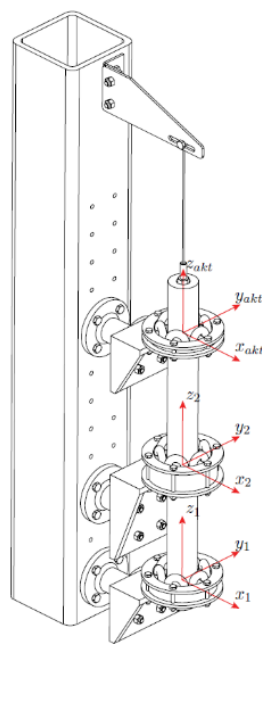

(b)

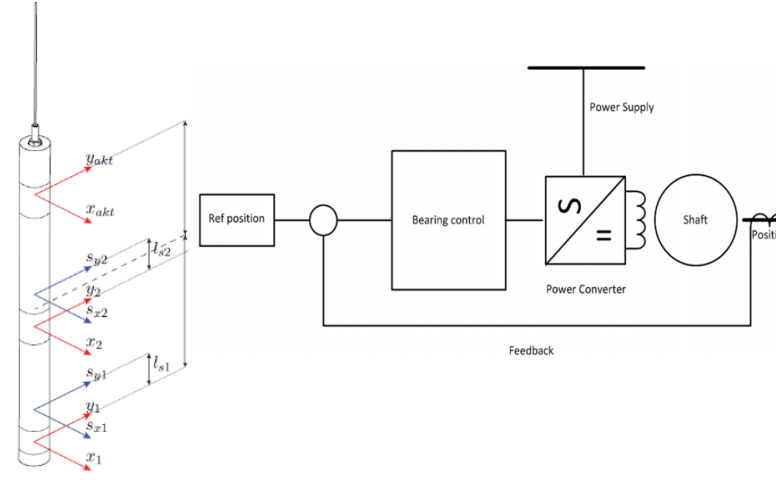

(c)

FIGURE 2. a) Simple free body diagram showing forces acting on bearings, [1]. b) Sketch of laboratory arrangement, [1]. Left is a sketch of the laboratory model, with two radial magnetic bearings and an actuator at the top to apply load. The right sketch, defines coordinate systems. Red coordinates are for the bearing, blue are sensor coordinates; dimensions are also given. Lengths defining sensor coordinates refer to the nearest bearing. Lengths between bearing centres refer to the centre of mass of the shaft, indicated by a dashed line c) Block diagram showing principle of operation of one direction of force for the controlled magnetic bearing. This system is repeated for each direction of force application [10].

The proposal is for two radial bearings, one above and one below the generator and two axial bearings in similar positions. The ratings of the proposed VAWT systems are as for the generator, above, and the required forces were calculated by the DeepWind team at DTU, Risø campus, who designed the blades, tower and floater, see Fig. $1 \mathrm{~b}$.

Rotor loads for a 2-bladed VAWT (including DeepWind concept pulsate with a twice per revolution component), the major source being aerodynamic loads, which contribute to large tower fatigue loads $[12,4]$, and together with Magnus forces these loads are supported by the journal bearings. In the $5 \mathrm{MW}$ conceptual design study, air forces on the NACA airfoils turned into edgewise rotor blade instabilities [12]. Torque ripples excited from the inappropriate turbine controls, were removed by using a simplified turbine control without solving the edgewise rotor blade instability [6]. At this point and further on, the bearings design is based on loads from the loads report [12]. The DeepWind turbine control is by means of a variable speed controller, which also provides controlled turbine start up and shut down. Due to the sub-sea position of the generator and bearings, sealing may represent a challenge-however previous solutions are known from submarine or underwater technologies. For a competitive cost of energy (COE), one of the requirements is to keep losses from whatever cause to a minimum. A major contribution comes from the friction of the sea water on the rotating spar, leaving only little room for internal power consumption on functions such as magnetic field generation. The bearings are mounted close to the generator at the bottom of the VAWT structure, well below sea level.

All forces, radial, axial and rotational, arising from the action of the wind and sea are supported by the bearings and transmitted to the structure and thence to the mooring system. The forces must be transmitted both during rotation and at standstill, making a purely hydro-dynamic bearing impractical. This led to a controlled magnetic bearing being proposed. 
The relationship between the bearings and the sea is very similar to that facing the generator, as both are electrically excited. The effect of waves and currents (magnitude, occurrence, direction) on the bearings is site dependent and needs to be addressed in detail. As a result of the large forces to be transmitted, and the need to maintain the centering of the generator rotor in the air-gap, the structural support of the bearings must be very strong and rigid.

\section{FUNCTION OF THE BEARINGS}

The bearings must transmit all forces from the wind turbine and floater to the mooring system, see Fig. 1c. These forces may be resolved into axial forces and radial forces. They arise due to the action of the wind or the water on the wind turbine system. This facility must be available whether the wind turbine is rotating or not. A controlled magnetic bearing system offers the required functions.

\section{PROPOSED CONSTRUCTION OF THE BEARINGS}

The function of a controlled magnetic bearing is to apply the required force in the required direction. This could be achieved using an electrically excited soft magnetic construction, or by a hybrid system comprising electrically excited soft magnetic system operating on a permanent magnet system. For the DeepWind project, a separately excited soft magnetic system was proposed to give maximum flexibility. An example of the magnetic circuit of such a system is shown diagrammatically in Fig. 3c.

Each flux path can only apply attractive force dependent on the coil current and the local air-gap, Fig. 11. The principle of the control is that an increase in air-gap causes an increase in current and therefore force. In the case of a radial bearing the position of the shaft is fed back to the controller, Fig. 4. As the system is a soft magnetic system, it is only necessary for the controller to provide DC to the coils, and this will cause the minimum iron loss in the bearing. Each radial bearing is arranged to provide force in three equally spaced directions. Axial bearings function in a similar fashion, but each bearing can attract in one direction along the shaft axis only. If the shaft position is measured to be central to the journal bearing, no winding current is applied, and no forces are induced. If the shaft is deflected from the central position, forces are applied by exciting the appropriate windings, to return it to the central position. By controlling the bearing in this way, force can be applied and the clearance maintained with or without the shaft rotating providing the power supply is available. The bearing control may be implemented in a single DSP for all eight directions of force, but a dedicated power converter and position sensor are required for each direction of force. The resultant forces acting at the bottom of the VAWT were resolved into radial forces and axial force, Fig. 5. The values of the force vectors were supplied by [5].

To ensure concentricity of the generator rotor and stator, the air-gap of the journal bearing is about half that of the generator, $6 \mathrm{~mm}$, on the latest $5 \mathrm{MW}$ design, giving $3 \mathrm{~mm}$ on the full-size journal bearing, and scaled down to $0.5 \mathrm{~mm}$ on the laboratory model. 


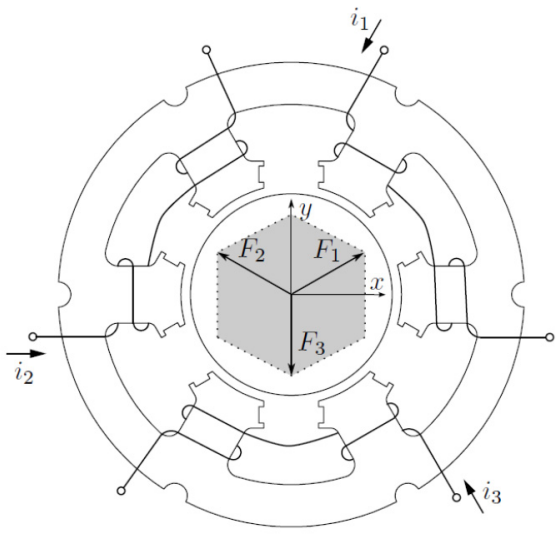

(a)

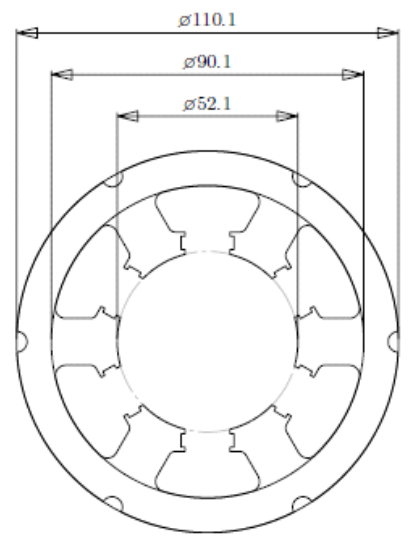

(b)

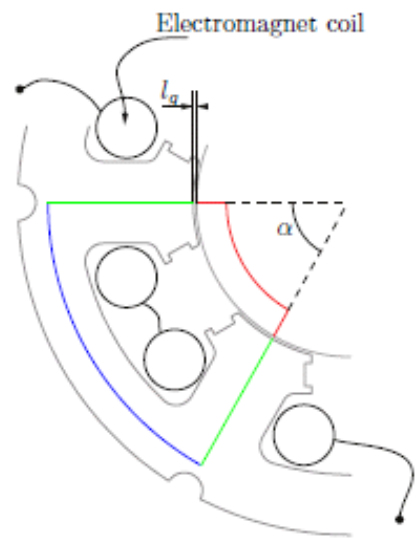

(c)

FIGURE 3. a) Sketch showing space vectors of force as they are excited by currents flowing in the coils for a radial bearing, [1]. b) cross-section of the stator core used for the laboratory model journal bearings. [1] c) Sketch showing a diagram of the mean flux path of one electromagnet of the laboratory model. the rotor flux path is shown in red, the radial flux path is green and the stator flux path is blue. [1].

\section{MATHEMATICAL MODEL AND VERIFICATION OF THE MODEL}

The journal bearing system was modelled in steady state to design the bearing, and with dynamic modelling to design the control and to study the bearing behavior. The models were validated using a laboratory model, [1].

The journal bearing comprises the shaft to be supported and a stator of electric sheet steel with windings fitted in slots. A structural FEM model is illustrated in Fig. 20. The winding is connected in three sections, enabling the bearings to supply controlled force in three directions. A sector of the laboratory model is shown in Fig. 9. The mean flux path is shown in colour. Current in the winding induces radial force only. A photo of the laboratory model is shown in Fig. 10.

The Steady State and Dynamic Models were developed in three regimes, mechanical, electrical and magnetic, and associated to form a single model. A laboratory model using a $52.1 \mathrm{~mm}$ diameter shaft and a $110.1 \mathrm{~mm}$ outer diameter stator was used to study the behaviour of the bearing and validate the models, giving some $60 \mathrm{~N}$ max. tested load. The results were then extrapolated to study the DeepWind 5 MW (load $640 \mathrm{kN}$, shaft 3 m diameter) and $20 \mathrm{MW}$ bearings.

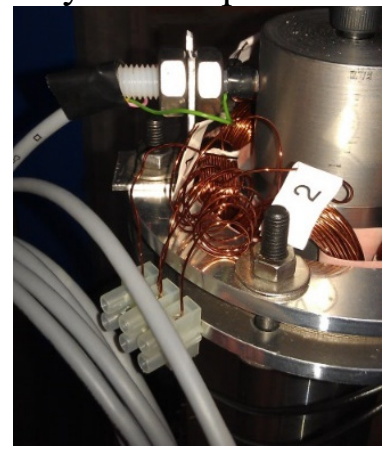

(a)

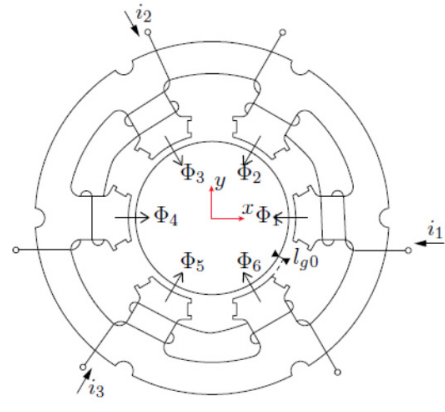

(b)

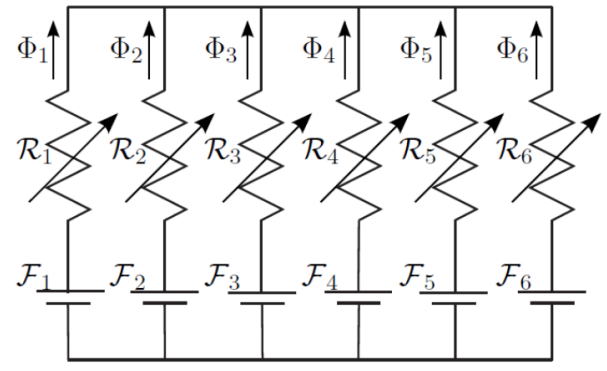

(c)

FIGURE 4. a) Photo of one laboratory bearing showing winding and shaft position sensor. [1]. b) Diagrammatic cross-section of the laboratory model of the radial bearing, showing the directional definition of current and flux. [1] c) Simple magnetic equivalent circuit of the radial controlled magnetic bearing used for calculations. [1]. 
Initially, the mechanical system of the laboratory model was modelled assuming a rigid rotor. Later, a flexible rotor model was added, to enable analysis of the response of the DeepWind bearings. The rigid rotor model refers to the small scale model, shown in Fig. 6. The Lagrangian formulation was used:

$$
\frac{d}{d t}\left(\frac{d \mathcal{L}}{d \dot{\vec{q}}}\right)-\frac{d \mathcal{L}}{d \dot{\vec{q}}}=\vec{Q} \quad \mathcal{L}=T-V
$$

Where $\mathcal{L}$ is defined as the difference between kinetic energy, $T$, and potential energy, $V$. The shaft is considered as a free body with five degrees of freedom, three rotational and two translational as the shaft of the laboratory model is fixed in the axial direction. The generalized coordinates are given by:

$$
\overrightarrow{\mathrm{q}}=\left[\begin{array}{llll}
x & y & \theta_{x} & \theta_{y}
\end{array}\right]^{T}
$$

Where $\overrightarrow{\mathrm{q}}$ is a vector describing four coordinates of the centre of mass. The fifth coordinate, $\theta_{z}$, is not included in (2), as $\dot{\theta}_{z}=\omega_{z}$ is assumed constant, given rotational symmetry around the $z$ axis. Using a succession of transforms, more closely described in [10], the dynamic equation, referred to bearing coordinates, and in terms of bearing forces, becomes:

$$
\begin{aligned}
& T_{1} \cdot \vec{Q}_{c}=M \cdot T_{2}^{-1} \cdot \ddot{\vec{x}}+G \cdot T_{2}^{-1} \cdot \dot{\vec{x}} \\
& \vec{Q}_{c}=T_{1}^{-1} \cdot M \cdot T_{2}^{-1} \cdot \ddot{\vec{x}}+T_{1}^{-1} \cdot G \cdot T_{2}^{-1} \cdot \dot{\vec{x}} \\
& \vec{Q}_{c}=M_{c} \cdot \ddot{\vec{x}}+G_{c} \cdot \dot{\vec{x}}
\end{aligned}
$$

Where $T_{1}$ is a transform to refer the actual forces to bearing forces:

$$
\begin{aligned}
& T_{1} \cdot \vec{Q}_{c}=M \cdot T_{2}^{-1} \cdot \ddot{\vec{x}}+G \cdot T_{2}^{-1} \cdot \dot{\vec{x}} \\
& \vec{Q}_{c}=T_{1}^{-1} \cdot M \cdot T_{2}^{-1} \cdot \ddot{\vec{x}}+T_{1}^{-1} \cdot G \cdot T_{2}^{-1} \cdot \dot{\vec{x}} \\
& \vec{Q}_{c}=M_{c} \cdot \ddot{\vec{x}}+G_{c} \cdot \dot{\vec{x}}
\end{aligned}
$$

Or

$$
\vec{Q}=T_{1} \cdot \vec{Q}_{c}
$$

The bearing and actuator coordinates are referred to the coordinates of the centre of mass:

$$
\begin{aligned}
& {\left[\begin{array}{l}
x_{1} \\
y_{1} \\
x_{2} \\
y_{2}
\end{array}\right]=\left[\begin{array}{cccc}
1 & 0 & 0 & -l_{1} \\
0 & 1 & l_{1} & 0 \\
1 & 0 & 0 & -l_{2} \\
0 & 1 & l_{2} & 0
\end{array}\right]\left[\begin{array}{c}
x \\
y \\
\theta_{x} \\
\theta_{y}
\end{array}\right]} \\
& \text { or } \\
& \vec{x}=T_{2} \cdot \vec{q}
\end{aligned}
$$

And a similar transform was applied for the sensor:

$$
\begin{aligned}
& {\left[\begin{array}{l}
s_{x 1} \\
s_{y 1} \\
s_{x 2} \\
s_{y 2}
\end{array}\right]=\left[\begin{array}{cccc}
1 & 0 & 0 & l_{s 1}-l_{1} \\
0 & 1 & l_{1}-l_{s 1} & 0 \\
1 & 0 & 0 & l_{s 2}-l_{2} \\
0 & 1 & l_{2}-l_{s 2} & 0
\end{array}\right]\left[\begin{array}{l}
x \\
y \\
\theta_{x} \\
\theta_{y}
\end{array}\right]} \\
& \vec{s}=T_{3} \cdot \vec{q}
\end{aligned}
$$


Note that the application of the transforms in equations (3) \& (4) requires the use of a new mass matrix $M_{c}$ and gyroscopic matrix $G_{c} . T_{1}$ is not square and will not yield a unique solution. If actuator forces are neglected on the laboratory scale model, $T_{1}$ becomes square and the system, referred to bearing coordinates may be analysed:

$$
\ddot{\vec{x}}=T_{2} \cdot M^{-1} \cdot\left(T_{1} \cdot \vec{Q}_{c}+G \cdot T_{2}^{-1} \cdot \dot{\vec{x}}\right)
$$

The flexible rotor model assumed a collection of Bernoulli-Euler beam elements, neglecting transverse shear deformation. A Finite Element type of approach was adopted, to allow for different cross-section masses of the rotor. Initially, the general static deflection of the rotor was expressed as a cubic function:

$$
\phi=a_{1}+a_{2} \cdot z+a_{3} \cdot z^{2}+a_{4} \cdot z^{3}=\mathbf{z} \cdot \boldsymbol{a}
$$

The limits for the deflection function are:

- $\phi=\emptyset_{1}$ and $\phi_{z}=\theta_{1}$ for $z=0$

- $\phi=\emptyset_{2}$ and $\phi_{z}=\theta_{2}$ for $z=L$

where $\emptyset_{1}$ is the deflection at the left element boundary and $\theta_{1}$ is the slope of the left boundary. $\emptyset_{2}$ $\& \theta_{2}$ refer to the right boundary. Applying this to (8) yields:

$$
\begin{aligned}
& {\left[\begin{array}{l}
\emptyset_{1} \\
\theta_{1} \\
\emptyset_{2} \\
\theta_{2}
\end{array}\right]=\left[\begin{array}{cccc}
1 & 0 & 0 & 0 \\
0 & 1 & 0 & 0 \\
1 & L & L^{2} & L^{3} \\
0 & 1 & 2 \cdot L & 3 \cdot L^{2}
\end{array}\right] \cdot\left[\begin{array}{l}
a_{1} \\
a_{2} \\
a_{3} \\
a_{4}
\end{array}\right]} \\
& \boldsymbol{d}=\boldsymbol{A} \cdot \boldsymbol{a}
\end{aligned}
$$

Or

$$
\boldsymbol{a}=A^{-1} \cdot \boldsymbol{d}
$$

Substituting (9) into (8) gives:

$$
\phi=\mathbf{z} \cdot \boldsymbol{A}^{-\mathbf{1}} \cdot \boldsymbol{d}=\mathbf{N} \cdot \boldsymbol{d}
$$

Where $\mathbf{N}$ is the shape function. The deflection function becomes in the $x$ and $y$ directions:

$$
\begin{aligned}
& \tilde{\mathbf{x}}=x_{1} \cdot N_{1}+\theta_{y 1} \cdot N_{2}+x_{2} \cdot N_{3}+\theta_{y 2} \cdot N_{4} \\
& \tilde{\mathbf{y}}=y_{1} \cdot N_{1}+\theta_{x 1} \cdot N_{2}+y_{2} \cdot N_{3}+\theta_{x 2} \cdot N_{4}
\end{aligned}
$$

The time derivatives become:

$$
\begin{aligned}
& \mathbf{N}=\boldsymbol{z} \cdot \boldsymbol{A}^{-1} \\
& =\left[\begin{array}{lllll}
1-\frac{3 \cdot \mathbf{Z}^{2}}{L^{2}}+\frac{2 \cdot \mathbf{Z}^{3}}{L^{3}} & z-\frac{2 \cdot \mathbf{Z}^{2}}{L}+\frac{z^{3}}{L^{2}} & \frac{z^{2}}{L^{2}}-\frac{2 \cdot \mathbf{z}^{3}}{L^{3}} & -\frac{z^{2}}{L}+\frac{2 \cdot \mathbf{Z}^{3}}{L^{2}}
\end{array}\right] \\
& =\left[\begin{array}{llll}
N_{1} & N_{2} & N_{3} & N_{4}
\end{array}\right]
\end{aligned}
$$




$$
\begin{aligned}
& \dot{\tilde{\boldsymbol{x}}}=\dot{x}_{1} \cdot N_{1}+\dot{\theta}_{y 1} \cdot N_{2}+\dot{x}_{2} \cdot N_{3}+\dot{\theta}_{y 2} \cdot N_{4} \\
& \dot{\tilde{\boldsymbol{y}}}=\dot{y}_{1} \cdot N_{1}+\dot{\theta}_{x 1} \cdot N_{2}+\dot{y}_{2} \cdot N_{3}+\dot{\theta}_{x 2} \cdot N_{4}
\end{aligned}
$$

The kinetic energy stored in one element, $i$, is:

$$
T_{i}=\frac{1}{2} \cdot \frac{M_{i}^{(s)}}{L_{i}} \cdot \int_{0}^{L_{i}}\left(\dot{\widetilde{x}}^{2}+\dot{\widetilde{\boldsymbol{y}}}^{2}\right) d z
$$

The potential energy stored in a rod in bending may be written:

$$
V_{i}=\frac{1}{2} \cdot E_{i} \cdot I_{i} \cdot \int_{0}^{L_{i}}\left(\left(\frac{\partial^{2} \tilde{x}}{\partial z^{2}}\right)^{2}+\left(\frac{\partial^{2} \tilde{y}}{\partial z^{2}}\right)^{2}\right) d z
$$

The gyroscopic contribution to the kinetic energy is:

$$
\begin{aligned}
& T_{g y r_{i}}=\frac{1}{4} I_{z z} \cdot\left(\omega^{2}-2 \cdot \omega \cdot \dot{\theta}_{y 1} \cdot \theta_{x 1}\right)+ \\
& \frac{1}{4} I_{z z} \cdot\left(\omega^{2}-2 \cdot \omega \cdot \dot{\theta}_{y 2} \cdot \theta_{x 2}\right)
\end{aligned}
$$

Where the subscript 1 refers to the left boundary and 2 to the right boundary. The elemental Lagrangian model can now be solved:

$$
\begin{aligned}
& \mathcal{L}_{i}=T_{i}-V_{i} \\
& \frac{d}{d t}\left(\frac{\partial \mathcal{L}_{i}}{\partial \dot{\vec{q}}_{r}}\right)-\frac{\partial \mathcal{L}_{i}}{\partial \vec{q}_{r}}=m_{i} \cdot \ddot{\vec{q}}_{r}+g_{i} \dot{\vec{q}}_{r}-k_{i} \cdot \vec{q}_{r}
\end{aligned}
$$

Where the vector $\vec{q}_{r}$ is given by the degrees of freedom of the element:

$$
\vec{q}_{r}=\left[\begin{array}{llllllll}
x_{1} & y_{1} & \theta_{x 1} & \theta_{y 1} & x_{2} & y_{2} & \theta_{x 2} & \theta_{y 2}
\end{array}\right]
$$

And the elemental mass, gyroscopic and stiffness matrices are given by:

$$
\begin{gathered}
m_{i}=\frac{m}{420}\left[\begin{array}{cccccccc}
156 & 0 & 0 & 22 \cdot L & 54 & 0 & 0 & -13 \cdot L \\
0 & 156 & -22 \cdot L & 0 & 0 & 54 & 13 \cdot L & 0 \\
0 & -22 \cdot L & 4 \cdot L^{2} & 0 & 0 & 13 \cdot L & -3 \cdot L^{2} & 0 \\
22 \cdot L & 0 & 0 & 4 \cdot L^{2} & -13 \cdot L & 0 & 0 & -3 \cdot L^{2} \\
54 & 0 & 0 & 13 \cdot L & 156 & 0 & 0 & -22 \cdot L \\
0 & 54 & -13 \cdot L & 0 & 0 & 156 & 22 \cdot L & 0 \\
0 & 13 \cdot L & -3 \cdot L^{2} & 0 & 0 & 22 \cdot L & 4 \cdot L^{2} & 0 \\
-13 \cdot L & 0 & 0 & -3 \cdot L^{2} & 22 \cdot L & 0 & 0 & -4 \cdot L^{2}
\end{array}\right] \\
g_{i}=\left[\begin{array}{cccccccc}
0 & 0 & 0 & 0 & 0 & 0 & 0 & 0 \\
0 & 0 & 0 & 0 & 0 & 0 & 0 & 0 \\
0 & 0 & 0 & 1 / 2 \cdot J_{p} \cdot \omega & 0 & 0 & 0 & 0 \\
0 & 0 & -1 / 2 \cdot J_{p} \cdot \omega & 0 & 0 & 0 & 0 & 0 \\
0 & 0 & 0 & 0 & 0 & 0 & 0 & 0 \\
0 & 0 & 0 & 0 & 0 & 0 & 0 & 0 \\
0 & 0 & 0 & 0 & 0 & 0 & 0 & 1 / 2 \cdot J_{p} \cdot \omega
\end{array}\right]
\end{gathered}
$$




$$
k_{i}=\frac{E_{i} \cdot I_{i}}{L^{3}}\left[\begin{array}{cccccccc}
12 & 0 & 0 & 6 \cdot L & -12 & 0 & 0 & 6 \cdot L \\
0 & 12 & -6 \cdot L & 0 & 0 & -12 & -6 \cdot L & 0 \\
0 & -6 \cdot L & 4 \cdot L^{2} & 0 & 0 & 6 \cdot L & 2 \cdot L^{2} & 0 \\
6 \cdot L & 0 & 0 & 4 \cdot L^{2} & -6 \cdot L & 0 & 0 & 2 \cdot L^{2} \\
-12 & 0 & 0 & -6 \cdot L & 12 & 0 & 0 & -6 \cdot L \\
0 & -12 & 6 \cdot L & 0 & 0 & 12 & 6 \cdot L & 0 \\
0 & -6 \cdot L & 2 \cdot L^{2} & 0 & 0 & 6 \cdot L & 4 \cdot L^{2} & 0 \\
6 \cdot L & 0 & 0 & 2 \cdot L^{2} & -6 \cdot L & 0 & 0 & 4 \cdot L^{2}
\end{array}\right]
$$

The degrees of freedom of the elements are linked by assembling the mass, gyroscopic and stiffness matrices. As the topology under consideration is a vertical beam, the upper boundary degrees of freedom of each lower element are connected to the lower boundary degrees of freedom of the element just above. The form of the system equation is:

$$
\mathbf{Q}=\boldsymbol{M} \cdot \ddot{\vec{q}}+\boldsymbol{G} \cdot \dot{\vec{q}}+\boldsymbol{K} \cdot \vec{q}
$$

The forces applied to the bearings by the external mechanical system and any unbalanced forces arising in the generator must be opposed by reaction forces from the bearings. These are created by the action of the magnetic field in the air-gap. This must maintain the generator air-gap at its nominal value $\pm 10 \%$. This is to minimize noise and vibration and to prevent touchdown between the two. In a magnetic bearing, the reaction force is provided by the Maxwell's stress in the airgap magnetic field of the bearing. The model of the bearing magnetic circuit is shown diagrammatically in Fig. 12.

$$
R=\mu \frac{l}{A}=\mu_{0} \frac{l_{\text {gap }}}{A_{\text {pole }}} \text { and } \mathcal{F}=N \cdot \boldsymbol{i}
$$

In (26), and Fig. 12, the reluctance $\boldsymbol{R}$ is assumed to be the reluctance of the air-gap only. The magneto motive force (MMF) $\mathcal{F}$ is provided by current flowing in the winding.

The model is then used to estimate the magnetic flux density in the air-gap as a function of the three currents, $i_{1}, i_{2} \& i_{3}$. And the radial length of the air-gap $\boldsymbol{l}_{\text {gap }}$. Current in any direction in any of the three windings will cause a force of attraction between the rotor and the stator in a direction determined by the placing of the winding, and in magnitude by the square of the magnitude of the current. The force generated by the magnetic bearing is a function of the change of energy in the air-gap, usually expressed in magnetic terms as:

$$
W_{\text {mag }}=1 / 2 \cdot \frac{B_{g a p}^{2}}{\mu_{0}}
$$

Fig. 12 shows a magnetic equivalent circuit diagram of the magnetic bearing sketched in Fig. 11. This was used to estimate the magnetic flux induced by each current, assuming that all magnetomotive force (MMF) generated by current flowing in one of the coils is used to induce flux flowing through that coil. The reluctance is assumed to be that of the air-gap only. All reluctances are variable functions of the air-gap size.

Summing the fluxes and the MMFs: The inductance of each coil relates the magnetic field to the electric circuit, where:

$$
0=\sum_{k=1}^{6} \emptyset_{k}
$$


$0=\mathcal{F}_{k}-\mathcal{R}_{k} \cdot \emptyset_{k}+\mathcal{R}_{k+1} \cdot \emptyset_{k+1}-\mathcal{F}_{k+1} ; k=1,2 \ldots 5$

This gives six equations which can be expressed:

$$
\Phi_{n}=\frac{\sum_{k=1}^{6} \frac{\mathcal{F}_{n}-\mathcal{F}_{k}}{\mathcal{R}_{n} \mathcal{R}_{k}}}{\sum_{k=1}^{6} \frac{1}{\mathcal{R}_{k}}} ; n=1,2, \ldots .6
$$

Where each MMF is equal to the current flowing in the coil multiplied by the number of turns:

$$
\begin{aligned}
& \mathcal{F}_{1}=\mathrm{N} \cdot i_{1} ; \mathcal{F}_{2}=-\mathrm{N} \cdot i_{1} \\
& \mathcal{F}_{3}=\mathrm{N} \cdot i_{2} ; \mathcal{F}_{4}=-\mathrm{N} \cdot i_{2} \\
& \mathcal{F}_{5}=\mathrm{N} \cdot i_{3} ; \mathcal{F}_{6}=-\mathrm{N} \cdot i_{3} \\
& \mathrm{~L}=\frac{\lambda}{i}=\frac{\mathrm{N} \cdot \Phi}{i}
\end{aligned}
$$

By inspection of Figure11, mutual inductance may exist between coils, which makes a matrix of self- and mutual inductances necessary. The self-inductance of coil one is given by:

$$
\mathrm{L}_{11}=\frac{\lambda_{11}}{i_{1}}, \quad \lambda_{11}=\left.N \cdot\left(\Phi_{1}-\Phi_{2}\right)\right|_{i_{2}=0, i_{3}=0}
$$

Where $\lambda_{11}$ is the flux linkages of coil one induced by current flowing in coil one, when the other two currents are zero. The mutual inductance between coil one and coil three is given by:

$$
\mathrm{M}_{13}=\frac{\lambda_{13}}{i_{3}}, \quad \lambda_{13}=\left.N \cdot\left(\Phi_{1}-\Phi_{3}\right)\right|_{i_{1}=0, i_{2}=0}
$$

And the complete inductance matrix becomes:

$$
\mathrm{L}=\left[\begin{array}{lll}
L_{11}\left(\vec{q}_{m}\right) & M_{12}\left(\vec{q}_{m}\right) & M_{13}\left(\vec{q}_{m}\right) \\
M_{21}\left(\vec{q}_{m}\right) & L_{22}\left(\vec{q}_{m}\right) & \mathrm{M}_{23}\left(\vec{q}_{m}\right) \\
M_{31}\left(\vec{q}_{m}\right) & M_{32}\left(\vec{q}_{m}\right) & L_{33}\left(\vec{q}_{m}\right)
\end{array}\right]
$$

The reluctances are assumed to depend only on the shaft position. Leakage inductance is assumed to be zero. The force exerted by the magnetic bearing is a function of the change of energy in the air-gap, found by differentiation of the energy stored in the coil, since the reluctance of the shaft and stator iron are assumed constant, Fig. 11, Fig. 12:

$$
\begin{aligned}
& \mathrm{W}=\frac{1}{2} \cdot \vec{\imath}^{T} \cdot L(\vec{q}) \cdot \vec{\imath} \\
& \overrightarrow{\mathrm{Q}}_{n}=\frac{\partial W}{\partial q_{n}} ; n=1,2
\end{aligned}
$$

Where $\vec{Q}_{n}$ is the force vector generated by the magnetic field in the air-gap. Note that saturation and eddy current loss are neglected.

The current vector $\vec{\imath}$ is found from an electric circuit model. This is expressed as the voltage equation:

$$
\vec{u}=R_{\text {ohm }} \cdot \vec{\imath}+\frac{d}{d t}(L(\vec{q}) \cdot \vec{\imath})
$$

Differentiating the flux linkage term yields:

$$
\vec{u}=R_{\text {ohm }} \cdot \vec{\imath}+L(\vec{q}) \cdot \frac{d \vec{\imath}}{d t}+\sum_{k=1}^{2}\left(\frac{\partial L(\vec{q})}{\partial q_{k}} \cdot \frac{d q_{k}}{d t}\right) \cdot \vec{\imath}
$$

This model can be used to control the current and thus the force in the bearing. 
The system model for the model of Fig. 9 was linearized using a first order Taylor series and implemented in Simulink. Bearing 1 is the lower bearing and bearing 2 the upper Inputs to the system are the voltages applied by the controllers and the force vector applied by the actuator of the laboratory model. The model of Fig. 13 is an assembly of the mechanical, magnetic and electrical circuit models described above. The gyroscopic effect is neglected in this model as the angular variations were considered to be negligible.

The resistance of the windings was measured. The force was measured as a function of current for various deflections of the shaft and calculated using the reluctance network, and a finite element model, see Fig. 14. The results from the reluctance network method were close to those from the other two, enabling it to be programmed in a Digital Signal Processor for control purposes. See Fig. 13.

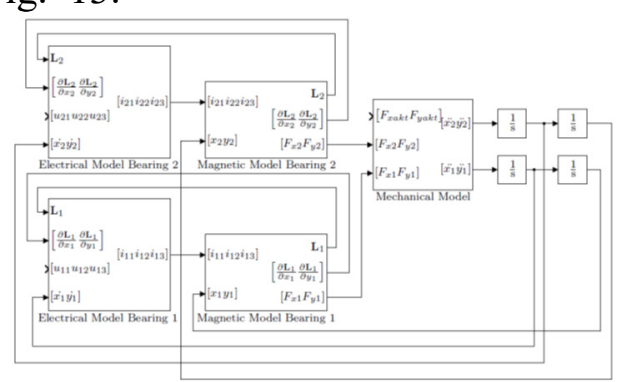

(a)

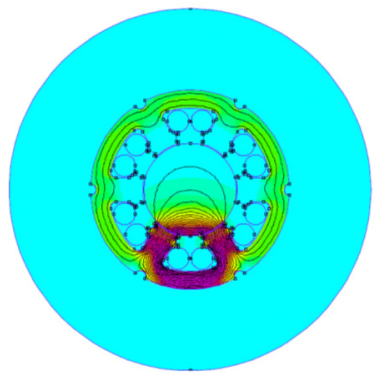

(b)
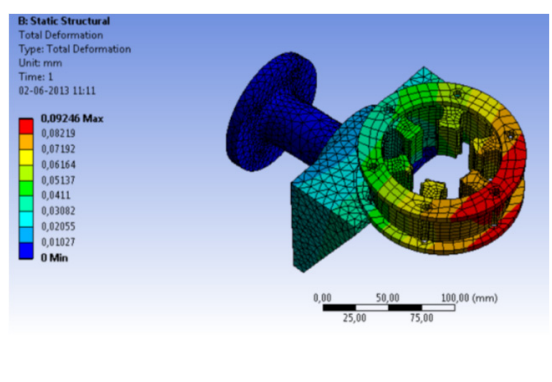

(c)

FIGURE 5. a) Simulink implementation of the system model of the laboratory test bearing arrangement of Fig. 6 [1]. b) Steady state 2D flux plot for laboratory model bearing [1]. c) static structural FEA of one laboratory model journal bearing stator showing deflection due to magnetically applied forces [1].

As the FEM results were close to the measured results, Fig. 15, they were used to adjust the zero deflection value of the reluctance model that was then tested against the FEM model for steady state deflections in the direction of the excited coil pair. Fig. 16 shows that when the air-gap is small; for deflections closer to the pole, the effect of saturation is evident for small currents; here about $2 \mathrm{~A}$. When the deflection is away from the pole the effect of saturation is very small, and occurs at higher current, $6 \mathrm{~A}$. However, for deflections close to the pole, the reluctance network model was judged to be adequate for the control system to function properly and generate only a small force, if any, at that pole. It must on the other hand, generate force at the other two poles, corresponding to a larger air-gap, where the assumption is justifiable. So the reluctance network model was judged to be adequate for use in the control system, allowing it to function properly. The controlled system was tested dynamically to verify the system model. The system was stabilized using a linear controller. The system was then perturbed by applying a step to the set point of the controller. The controller was a decentralized PD controller tuned to minimize differential noise:

$$
\begin{array}{cc}
\text { Bearing one: } & \text { Bearing two } \\
k_{p}=1678.5 & k_{p}=2228.0 \\
k_{d}=11.52 & k_{d}=18.20
\end{array}
$$

The results for two different step inputs, one positive, and one negative, are shown in Fig. 17. The measured results are compared with results from the Simulink program, utilizing the reluctance network. The two sets of results are acceptably close to each other. In Fig. 18 and Fig. 19 it may be seen that the simulated and measured current results are quite different. This need investigation, 
but is probably because the assumption of unsaturated iron is not valid. Visual comparison of the two sets of signals is difficult as the noise in the position signal was exacerbated in the differential part of the controller. However, this noise does not invalidate the results entirely and will hopefully be mitigated by a redesign of the circuitry.

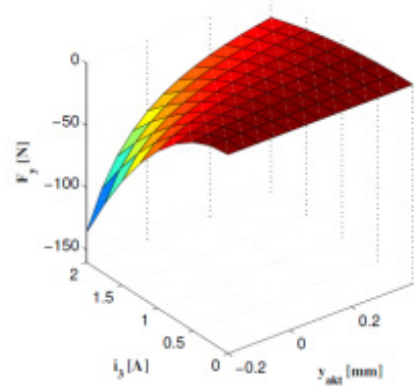

(a) Force by RNM.

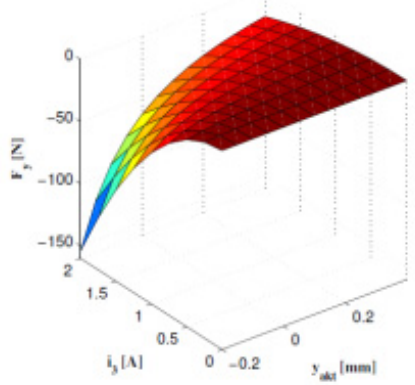

(b) Force by FEMM model.

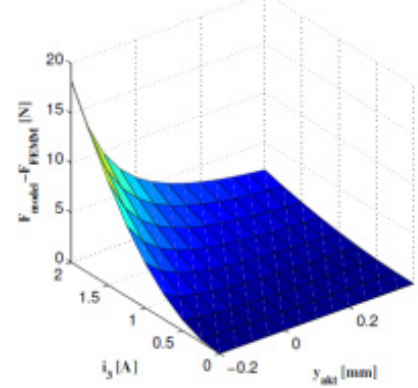

(c) Difference between RNM force and FEMM force.

FIGURE 6. Force calculated using the reluctance network model, the finite element model and the difference between them [1].

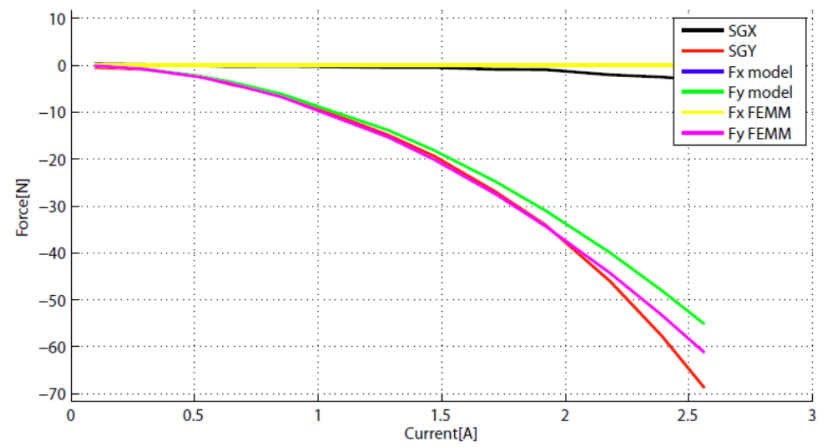

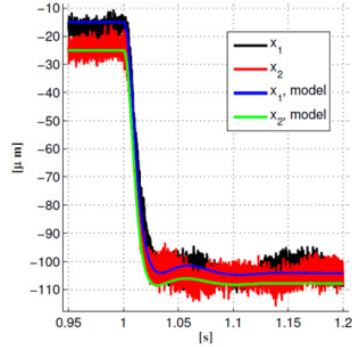

(a) Step of $-80 \mu \mathrm{m}$

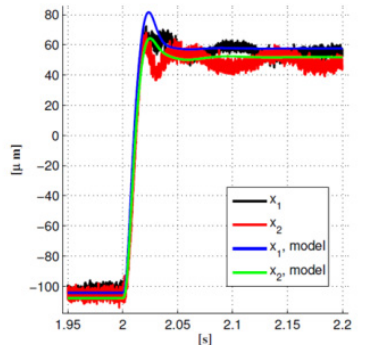

(b) Step of $160 \mu \mathrm{m}$

FIGURE 7. Left) Force measured at a y deflection of the shaft in the bearings of $0.17 \mathrm{~mm}$. Steady state results obtained from the reluctance network model and from the finite element model [1]. Right) Position step response of the shaft for two different step inputs. Measured results compared with simulated results [1].

\section{PROPOSED CONSTRUCTION OF THE DEEPWIND BEARINGS}

The system of controlled magnetic bearings requires the bearings themselves, and also a control system comprising a sensor for the shaft position, a feedback controller and a power converter. A controller and converter will be required for each direction of force, eight in all for two journal bearings and two thrust bearings. 


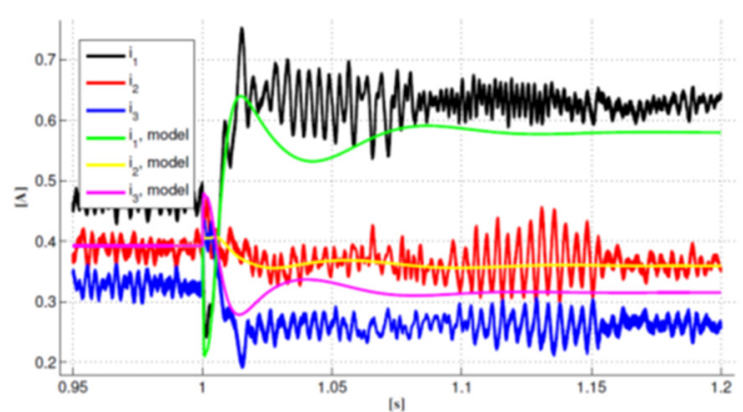

(a)

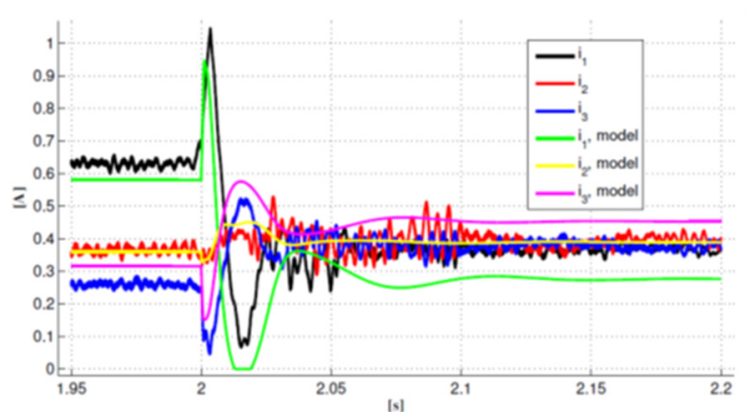

(b)

FIGURE 8. a) Measured and simulated currents for a $-80 \mu \mathrm{m}$ step. The cause of the errors is probably due to saturation effects in the stator iron [1]. b) Measured and simulated currents for a $160 \mu \mathrm{m}$ step. The cause of the errors is probably due to saturation effects in the stator iron [1].

\section{BEARINGS}

It is proposed to construct the DeepWind bearings in the same general manner as those for the laboratory model. However, because of the comparatively large diameter, it is proposed to use many poles for each direction of force and distribute the applied force over the 120 degrees between axes. The general shape of the active parts of the journal bearings will be similar to that of the generator, two thin-walled cylinders, one inside the other. For these to maintain their shape and avoid touchdown, they must be supported by strong, rigid supports that will transmit the forces with acceptably small deformation. As the forces involved are very large the construction becomes a very important part of the design but remains for further work.

The proposed preliminary bearing sizes are as shown in Table 2, provided that the shaft diameter, distance between centres and the applied force and moment vectors are not changed.

Although the mechanical and electromagnetic models of the bearing have been verified using the laboratory test rig, they will need to be modified to include all degrees of freedom anticipated for the Deep Wind system. Then the models will be used to redesign and predict the performance of the $5 \mathrm{MW}$ and $20 \mathrm{MW}$ bearings. Additional consideration is required for the sealing of the generator shaft. This will be dependent on the final design of the assembly, [9], [1].

\section{BEARING CONTROLLER AND CONVERTER}

The recommended control strategy for the full scale version was Full State Feedback - Integral Control and state Observer (FSFICO) as it yielded the best stall force performance although the most energy efficient strategy was the Centralized Space Vector Proportional Derivative (CSVPD) as this did not require a bias current to ensure linearity. The power converters were rated for continuous operation, six to give the value of $130 \mathrm{~kW}$ for radial bearings, and two to give $190 \mathrm{~kW}$ for axial bearings, although the anticipated long term power consumption was much smaller as it will depend on the actual force applied.

\section{DESIGN TOOL, ASSUMPTIONS AND SAFETY FACTORS}

The design tool made for the bearings was simpler than that for the generator reflecting the simpler construction of the bearing. The algorithm applied is illustrated in Table 1. As the iterations of the design included discussions with the blade, floater and mooring design teams, all iterations were 
manual. Separate files were generated for corresponding radial and axial bearings, but with identical run numbers. This enabled bearings to be designed in collaboration with the DeepWind consortium, [9].

The distribution of applied force vectors arising from the operation of the VAWT floating in the sea was calculated and supplied by the blade design team. To this was added unbalanced magnetic pull arising in the generator. From these values the maximum and mean design loads were calculated. Design rules were applied to modify the loads by applying a factor of safety and determine the basic bearing dimensions required. The electromagnetic material properties, including allowances for saturation, were used to determine the outer dimensions and dimension the windings, and to determine the electrical supply required to support the forces, thus dimensioning the controller.

TABLE 1 Pseudo-algorithm for bearing design tool.

\begin{tabular}{ll}
\hline \multicolumn{1}{c}{ Task } & \multicolumn{1}{c}{ Action } \\
\hline Initialize & Load Input values, material properties, cost of materials and \\
design rules. Increment the run identification number. & Calculate forces due to eccentricity in generator for max. \\
allowed eccentricity & Calculate forces regarded as max. load \\
& Calculate mean and max. bearing loads \\
& Calculate force values for each bearing, allowing for position \\
& Calculate required bearing area to support max. forces \\
& Determine required areas of bearings \\
& Determine number of slots \\
& Determine number of poles and coils \\
& Determine tooth and slot dimensions \\
& Determine back iron dimensions \\
& Determine outer diameter and length \\
& Determine ampere turns required \\
& Determine current required \\
& Calculate resistance and copper mass \\
& Calculate required voltage for max. forces \\
& Calculate magneto-motive force \\
Calculate coil current & Calculate material mass used \\
Finalize & Calculate costs \\
& Print numbered report to file \\
\hline
\end{tabular}

\section{SUMMARY AND CONCLUSION}

The controlled magnetic bearings for the DeepWind VAWT system have been introduced and described. The modelling methods and principles applied have been described. Extensive study of the mechanical construction is required, in order to support the loads and survive the environment without causing pollution of the sea. As the forces, moments and torque of the floating VAWT become very large, the supporting structure becomes very important and costly and needs careful design studies to minimize the material usage, while retaining the necessary rigidity and lifetime. Some special challenges remain, associated with the subsea environment and the low power frequencies recommended for high power VAWT duty. 
TABLE 2. Bearing design tool output of $5 \mathrm{MW}$ bearing

\begin{tabular}{|c|c|c|c|}
\hline \multirow{2}{*}{$\begin{array}{l}\text { Inputs } \\
\text { Shaft diameter }[\mathrm{m}]\end{array}$} & \multicolumn{3}{|c|}{ Bearings } \\
\hline & 5,35 & Radial Bearing & \\
\hline $\mathrm{F}_{\mathrm{x}} \quad[\mathrm{kN}]$ & 0 & Outer diameter & 5,765 \\
\hline$\sigma \mathrm{F}_{\mathrm{x}}[\mathrm{kN}]$ & 1176 & Overall length $\quad[\mathrm{m}]$ & 22,48 \\
\hline $\mathrm{F}_{\mathrm{y}} \quad[\mathrm{kN}]$ & 0 & Weight 1 bearing total [ton] & 592 \\
\hline$\sigma \mathrm{F}_{\mathrm{y}}[\mathrm{kN}]$ & 1176 & Max. power consumed $[\mathrm{kW}]$ & 1270 \\
\hline $\mathrm{F}_{\mathrm{z}}[\mathrm{kN}]$ & -2648 & & \\
\hline$\sigma \mathrm{F}_{\mathrm{z}}[\mathrm{kN}]$ & 588 & Axial Bearing & \\
\hline $\mathrm{M}_{\mathrm{x}}[\mathrm{kNm}]$ & 0 & Outer diameter & 8 \\
\hline$\sigma \mathrm{M}_{\mathrm{x}}[\mathrm{kNm}]$ & 6667 & Overall length & 0,36 \\
\hline $\mathrm{M}_{\mathrm{y}}[\mathrm{kNm}]$ & 0 & Weight 1 bearing total [ton] & 157,5 \\
\hline$\sigma \mathrm{M}_{\mathrm{y}}[\mathrm{kNm}]$ & 6667 & Max. power consumed $[\mathrm{kW}]$ & 188,4 \\
\hline
\end{tabular}

\section{ACKNOWLEDGMENTS}

The reported work is a part of the result of Work Package 3 of the DeepWind project which was supported by the European Commission, Grant 256769 FP7 Energy 2010- Future emerging technologies, and supported by the contributing national partner of the DeepWind consortium: DTU(DK), AAU(DK), TUDELFT(NL), TUTRENTO(I), DHI(DK), SINTEF(N), MARINTEK(N), MARIN(NL), NREL(USA), STATOIL(N), VESTAS(DK) and NENUPHAR(F). Asger B. Abrahamsen ${ }^{2}$ is acknowledged for support on editing the manuscript.

\section{REFERENCES}

1. H. Bjerregaard, K. Sloth and R. R. Thygesen, "Design of Active Electromagnetic Bearing for Darrieus Type Wind Turbines", MSc thesis, Aalborg University, June 2013.

2. S. Carstensen, X. Mandviwalla, L. Vita and U. S. Paulsen, "Lift of a Rotating Circular Cylinder in Unsteady Flows." In The Twenty-second International Offshore and Polar Engineering Conference 2012 Jan 1. International Society of Offshore and Polar Engineers.

3. DeepWind, 2015, http://www.deepwind.eu/ - reports, photos and videos.

4. C. Galinos, T. J. Larsen, H. A. Madsen and U. S. Paulsen, "Vertical axis wind turbine design load cases investigation and comparison with horizontal axis wind turbine" Elsevier Energy Procedia 2016 Vol 94, pp 319328. doi.org/10.1016/j.egypro.2016.09.190

5. K.A. Kragh and H. A. Madsen, "2nd Iteration Design Loads for the DeepWind 5MW Turbine", DTU Wind Energy, Risø Campus, 2013.

6. R. Meyer, "Stability Analysis of Multi-Megawatt Darrieus-Type Floating Vertical Axis Wind Turbines", MSc Thesis, DTU Wind Energy-M-0099, June 2016.

7. U. S. Paulsen, DeepWind internal DeepWind project communication, DTU, Risø Campus, March 2015.

8. U. S. Paulsen, M. Borg, H. A. Madsen, T. F. Pedersen, J. Hattel, E. Ritchie, C. S. Ferreira, H. Svendsen, P. A. Berthelsen, C. Smadja, "Outcomes of the DeepWind conceptual design" Energy Procedia Volume 80, 2015, Pages 329-341, doi:10.1016/j.egypro.2015.11.437

9. E. Ritchie, "Design tools for submersible converter", DeepWind WP3 Deliverable report D3.32, E.U. FP7 Grant number 256769, 2014-08-31, 390 pp.

10. E. Ritchie, K. Leban and U. S. Paulsen, "Electrical aspects of the DeepWind 5 MW floating Vertical Axis Wind Turbine", Sixth International Symposium on Energy Challenges and Mechanics, Inverness, August 2016.

11. E. Ritchie, H. Bjerregaard, K. Sloth and R. R. Thygesen, "Development tool for Magnetic Bearing design", D3.3, Tech. Report, EU FP7 project, Future Deep Sea Wind Turbine Technologies, 2013.

12. D. R. Verelst, H. A. Madsen, K. A. Kragh and F. Belloni "Detailed Load Analysis of the baseline 5 MW DeepWind Concept." DTU Wind Energy, Technical Report E-0057, 2014.

13. L. Vita, U. S. Paulsen and T. Friis Pedersen, "A novel floating offshore wind turbine concept: new developments." DeepWind project report, 2010. 